\title{
The Effect of Polyterpenol Thin Film Surfaces on Bacterial Viability and Adhesion
}

\author{
Kateryna Bazaka ${ }^{1}$, Mohan V. Jacob ${ }^{1}$, Vi Khanh Truong ${ }^{2}$, Russell J. Crawford ${ }^{2}$ and \\ Elena P. Ivanova ${ }^{2, *}$
}

1 Electronic Materials Research Lab, School of Engineering and Physical Sciences, James Cook University, Townsville QLD 4811, Australia; E-Mails: katia.bazaka@my.jcu.edu.au (K.B.); mohan.jacob@jcu.edu.au (M.V.J.)

2 Faculty of Life and Social Sciences, Swinburne University of Technology, P.O. Box 218, Hawthorn, Victoria 3122, Australia; E-Mails: vtruong@swin.edu.au (V.K.T.); rcrawford@swin.edu.au (R.J.C.)

* Author to whom correspondence should be addressed; E-Mail: eivanova@ @win.edu.au; Tel.: +61-3-9214-5137; Fax: +61-309214-5921.

Received: 20 November 2010; in revised form: 23 December 2010 / Accepted: 25 January 2011 / Published: 28 January 2011

\begin{abstract}
The nanometer scale surface topography of a solid substrate is known to influence the extent of bacterial attachment and their subsequent proliferation to form biofilms. As an extension of our previous work on the development of a novel organic polymer coating for the prevention of growth of medically significant bacteria on three-dimensional solid surfaces, this study examines the effect of surface coating on the adhesion and proliferation tendencies of Staphylococcus aureus and compares to those previously investigated tendencies of Pseudomonas aeruginosa on similar coatings. Radio frequency plasma enhanced chemical vapor deposition was used to coat the surface of the substrate with thin film of terpinen-4-ol, a constituent of tea-tree oil known to inhibit the growth of a broad range of bacteria. The presence of the coating decreased the substrate surface roughness from approximately $2.1 \mathrm{~nm}$ to $0.4 \mathrm{~nm}$. Similar to $P$. aeruginosa, $S$. aureus presented notably different patterns of attachment in response to the presence of the surface film, where the amount of attachment, extracellular polymeric substance production, and cell proliferation on the coated surface was found to be greatly reduced compared to that obtained on the unmodified surface. This work suggests that the antimicrobial and antifouling coating used in this study could be effectively integrated into
\end{abstract}


medical and other clinically relevant devices to prevent bacterial growth and to minimize bacteria-associated adverse host responses.

Keywords: nanoarchitecture; plasma polymerization; terpinen-4-ol

\section{Introduction}

Biomaterial-associated infections remain a major hindrance to the long-term utilization of most implanted or intravascular devices, including orthopedic prostheses, artificial valves, urinary tract and cardiovascular catheters, intraocular lenses and dentures [1,2]. Bacterial attachment and subsequent biofilm formation frequently results in indwelling device related infections and device failure [3,4]. In their biofilm state, bacteria are less susceptible to host defense mechanisms and systemic antibiotics, and also to detachment due to flow conditions. The presence of these biofilms can often cause an infection, often requiring the surgical removal of the infected device [5]. The mechanism of bacterial adhesion is complex, with initial reversible physicochemical interactions being followed by intricate irreversible molecular and cellular interactions. When the distance between the bacterial cell and other cells or abiotic surfaces is larger than $50 \mathrm{~nm}$, the interactions between these two entities are nonspecific and are directly related to the distance and the dispersive component of free energy characteristics pertinent to these two surfaces [6]. The nature of these forces, i.e., whether they are attractive or repulsive, will either facilitate the bacterial attachment or prevent the cell from engaging into the molecular or cellular phase of adhesion. When the distance separating these surfaces becomes less than $5 \mathrm{~nm}$, chemical interactions such as hydrogen bonding, ionic and dipole interactions, hydration and/or hydrophobic interactions become significant, often resulting in a more stable adhesion between the microorganism and the surface [7]. Various polymeric structures such as capsules, fimbriae, pili, and slime that can be present on the surface of the bacterial cell engage in the molecular specific irreversible reactions with the chemical features of the tissue or abiotic surface. Therefore, in order to effectively control the attachment and adhesion of the cells to the surfaces, it is imperative to understand the surface properties and the physicochemical interactions associated with the initial events of cell adhesion. An obstacle to obtaining this understanding is that the relative contributions of the molecular and physical interactions that govern bacterial adhesion to biomaterials are yet to be fully interpreted.

There is much debate as to the extent to which the nanometer scale surface topography of a solid substrate influences bacterial adhesion and their subsequent proliferation to form biofilms [8,9]. Investigations on the adhesion of Pseudomonas aeruginosa to poly(methyl methacrylate) contact lenses identified that surfaces with a root-mean-square (RMS) roughness parameter of $14 \mathrm{~nm}$ or above tended to experience an increased extent of micro-organism attachment [10]. Other studies on the attachment preferences of human pathogens P. fluorescens and Staphylococcus aureus have demonstrated that the topography of micro-rough titanium surfaces can influence the extent of cell attachment and growth, with cells showing propensity for growth in the trenches of the surface in long rows [11,12], whilst the attachment response of these bacteria towards smooth surfaces did not follow a distinct pattern $[11,13]$. A few early studies reported that surface roughness was a 'minor factor' in 
the attachment mechanism of bacteria, in that the bacteria displayed no preference for adhesion to surface features such as scratches or grooves [8,9]. However, preferential adherence of bacteria to grooved and braided surfaces was found by Scheuerman et al., who attributed this increased attachment propensity as being due to the presence of an increased surface area [13]. More specifically, in situations where the size of the surface features was comparable to the size of the bacterium, the bacteria-surface contact area is at a maximum and hence the binding potential of the bacteria was increased [14]. In cases where the surface features were significantly smaller than the bacterial size, the contact area was reduced, resulting in a reduced extend of binding [15]. The level of extracellular polymeric substance (EPS) production and bacterial cell morphology have also been shown to be affected by the surface architecture $[11,16,17]$. Nano-patterning of gold surfaces has been demonstrated to enhance the localized attachment of $P$. fluorescens in the trenches of the surfaces compared to that obtained using native gold surfaces, with cells showing limited EPS production and reduced cell size compare to those attached onto non-nano-patterned surfaces [11]. Our recent investigation on the effect of surface roughness on the attachment behavior and production of extracellular polymeric substances for the Gram-positive coccoid pathogen, S. aureus, and Gram-negative rod shaped bacterium, $P$. aeruginosa, have shown that both pathogens exhibit a greater propensity for adhesion to glass and polymer surfaces that are smooth on the scale of nanometers, resulting in elevated cellular metabolic activity, augmented production of extracellular polymeric substances, and increased number of bacterial cells undergoing attachment [17-19].

Numerous surface modification techniques, such as radio frequency (RF) plasma modification, surface abrasion, chemical coating, and chemical grafting can be employed to change surface properties of the substrate so as to inhibit or promote bacterial adhesion and biofilm formation [20-26]. In this context, the present study is an extension of our previous work on the development of a novel organic polymer coating for the prevention of growth of medically significant bacteria on three-dimensional solid surfaces. In this study, the effect of surface coating with terpinen-4-ol on the adhesion and proliferation tendencies of $S$. aureus were examined and compared to those previously reported for $P$. aeruginosa. The surfaces of substrates were modified by the fabrication of a polyterpenol thin film derived from terpinen-4-ol using RF plasma enhanced chemical vapor deposition. Terpinen-4-ol is a constituent of tea-tree oil and its monomer (liquid) form is known to inhibit growth of a broad range of bacteria [27-30]. Surfaces of coatings produced from terpinen-4-ol are known to be smooth on the scale of nanometers and defect free, with good adhesion to the substrate and good stability [31-34]. Since previous studies have shown $S$. aureus and P. aeruginosa to preferentially attach and adhere to surfaces that are smooth on the nanometer scale, this study examines the influence of surface architecture on the antifouling properties of the polyterpenol coating.

\section{Results}

\subsection{Surface Characterization}

As indicated by the analysis of the high resolution atomic force microscope (AFM) images (Figure 1), the surface topography of the glass substrates was altered at the nanometer scale by the application of thin polymer coating. The key parameters of the surface topography are summarized in Table 1 and confirmed by a statistical analysis of the surface roughness parameters of polyterpenol 
thin films fabricated under $10 \mathrm{~W}$ and $25 \mathrm{~W}$ RF power conditions. The surfaces were described in terms of such roughness parameters as the average surface roughness $\left(R_{\mathrm{a}}\right)$ which is related to the average/absolute deviation of the surface irregularity from the mean line over one sampling length, the root-mean-square roughness $\left(R_{\mathrm{q}}\right)$ or RMS calculated as the standard deviation of the distribution of surface height, and the peak-to-peak roughness $\left(R_{\max }\right)$ which describes the vertical distance between the highest peak and the lowest valley along the assessment length of the surface profile.

Figure 1. Typical two-dimensional (2D) atomic force microscope (AFM) images and surface profiles of glass (a and $\mathbf{d}$, respectively) and polyterpenol thin film surfaces fabricated at $10 \mathrm{~W}$ (b and e, respectively) and $25 \mathrm{~W}$ (c and fospectively) from an approximately $10 \mu \mathrm{m} \times 10 \mu \mathrm{m}$ scanned area.
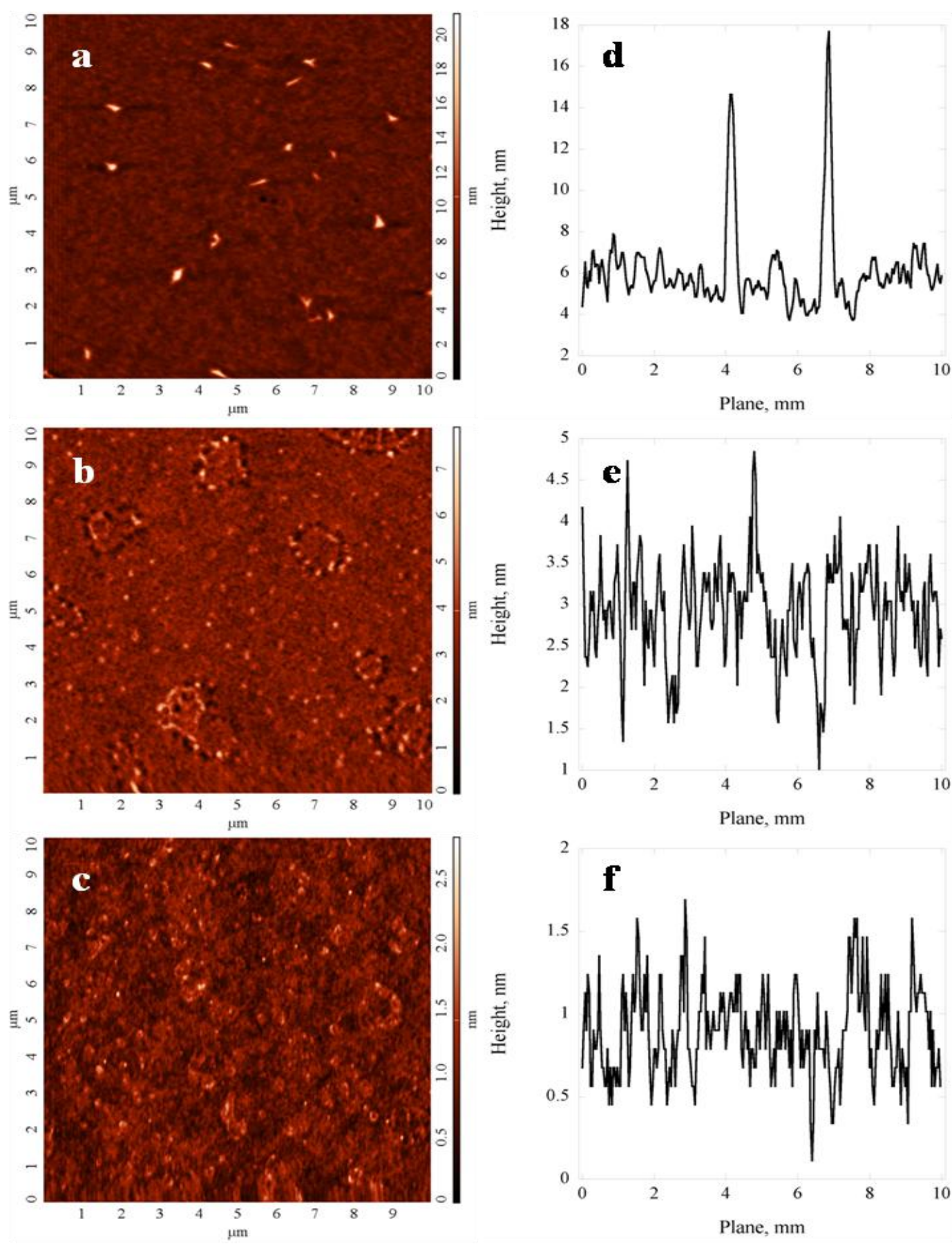
Table 1. Surface hydrophobicity, surface tension, surface free energy, and atomic force microscope (AFM) analysis of the roughness parameters for the modified and substrate (glass) surfaces.

\begin{tabular}{|c|c|c|c|c|c|c|}
\hline \multirow[b]{3}{*}{$\begin{array}{c}\text { Roughness parameters } \\
(n m) \pm S D \\
\end{array}$} & \multicolumn{2}{|c|}{ Unmodified substrate } & \multirow{2}{*}{\multicolumn{2}{|c|}{$\begin{array}{c}\text { Polyterpenol } 10 \mathrm{~W} \\
\text { Scanning areas }(\mu \mathrm{m})\end{array}$}} & \multicolumn{2}{|c|}{ Polyterpenol 25 W } \\
\hline & \multirow[b]{2}{*}{$1 \times 1$} & \multirow[b]{2}{*}{$10 \times 10$} & & & \multirow[b]{2}{*}{$1 \times 1$} & \multirow[b]{2}{*}{$10 \times 10$} \\
\hline & & & $1 \times 1$ & $10 \times 10$ & & \\
\hline Maximum peak height $R_{\max }$ & $8.48 \pm 0.96$ & $30.45 \pm 2.55$ & $2.25 \pm 0.24$ & $17.50 \pm 3.42$ & $1.24 \pm 0.21$ & $3.56 \pm 0.76$ \\
\hline Average Roughness $R_{a}$ & $0.40 \pm 0.05$ & $1.96 \pm 0.12$ & $0.25 \pm 0.05$ & $1.32 \pm 0.27$ & $0.13 \pm 0.02$ & $0.24 \pm 0.03$ \\
\hline Root Mean Square $R_{q}$ & $0.64 \pm 0.08$ & $2.13 \pm 0.12$ & $0.32 \pm 0.05$ & $1.58 \pm 0.32$ & $0.17 \pm 0.03$ & $0.40 \pm 0.03$ \\
\hline Surface skewness $R_{\text {skw }}$ & $3.20 \pm 0.37$ & $0.34 \pm 0.11$ & $-0.09 \pm 0.12$ & $-0.63 \pm 0.06$ & $0.06 \pm 0.02$ & $-0.04 \pm 0.28$ \\
\hline Coefficient of kurtosis $R_{\text {kur }}$ & $21.85 \pm 1.71$ & $5.27 \pm 0.45$ & $2.99 \pm 0.34$ & $3.06 \pm 0.10$ & $2.88 \pm 0.06$ & $3.40 \pm 0.37$ \\
\hline \multicolumn{7}{|c|}{ Contact angle $\left({ }^{\circ}\right)$} \\
\hline$\theta_{\mathrm{W}}{ }^{\mathrm{a}}$ & \multicolumn{2}{|c|}{$8.3 \pm 0.7$} & \multicolumn{2}{|c|}{$62.7 \pm 4.0$} & \multicolumn{2}{|c|}{$68.7 \pm 3.1$} \\
\hline$\theta_{\mathrm{EG}}$ & \multicolumn{2}{|c|}{$26.5 \pm 1.3$} & \multicolumn{2}{|c|}{$59.8 \pm 2.4$} & \multicolumn{2}{|c|}{$58.7 \pm 0.5$} \\
\hline$\theta_{\mathrm{D}}$ & \multicolumn{2}{|c|}{$43.8 \pm 0.8$} & \multicolumn{2}{|c|}{$38.2 \pm 0.8$} & \multicolumn{2}{|c|}{$38.1 \pm 0.8$} \\
\hline \multicolumn{7}{|l|}{ Surface tension $\left(\mathrm{mJ} / \mathrm{m}^{2}\right)$} \\
\hline$\gamma^{\mathrm{LWb}}$ & \multicolumn{2}{|c|}{37.6} & \multicolumn{2}{|c|}{40.5} & \multicolumn{2}{|c|}{40.5} \\
\hline$\gamma^{\mathrm{AB}}$ & \multicolumn{2}{|c|}{1.54} & \multicolumn{2}{|c|}{9.3} & \multicolumn{2}{|c|}{5.4} \\
\hline$\gamma^{+}$ & \multicolumn{2}{|c|}{0.01} & \multicolumn{2}{|c|}{0.7} & \multicolumn{2}{|c|}{0.4} \\
\hline$\gamma^{-}$ & \multicolumn{2}{|c|}{73.6} & \multicolumn{2}{|c|}{30} & \multicolumn{2}{|c|}{20.6} \\
\hline$\gamma_{\mathrm{TOT}}$ & \multicolumn{2}{|c|}{39.2} & \multicolumn{2}{|c|}{49.8} & \multicolumn{2}{|c|}{45.9} \\
\hline
\end{tabular}

W, Water; EG, ethylene glycol; D, diiodomethane; Surface free energies components: Lifshitz-van der Waals $\left(\gamma^{\mathrm{LW}}\right)$, acid/base $\left(\gamma^{\mathrm{AB}}\right)$, electron acceptor $\left(\gamma^{+}\right)$and electron donor $\left(\gamma^{-}\right)$components.

Independent of deposition power, the average surface roughness $\left(R_{\mathrm{a}}\right)$, root mean square roughness $\left(R_{\mathrm{q}}\right)$, and peak-to-peak roughness $\left(R_{\max }\right)$ appeared to be statistically significantly lower $(p<0.05)$ on the coated glass substrates for both deposition conditions compared to unmodified glass (Table 1). Notably, polyterpenol thin films deposited by means of RF plasma polymerization were confirmed to be smooth, defect free and homogenous, in agreement with a previously published report [32]. Amongst polyterpenol films, coatings fabricated at $25 \mathrm{~W}$ were characterized by lower average $\left(R_{\mathrm{a}}\right)$ and RMS $\left(R_{\mathrm{q}}\right)$ surface roughness parameters, and peak-to-peak roughness $\left(R_{\max }\right)$ compared to those deposited at $10 \mathrm{~W}$, with the difference being statistically significant $(p<0.05)$. The observed reduction in roughness is expected for plasma polymer films deposited at higher RF power due to increased degree of fragmentation associated with higher energy of the plasma field. The surface skewness $\left(R_{\mathrm{skw}}\right)$ and coefficient of kurtosis $\left(R_{\mathrm{kur}}\right)$ values were determined to be independent of the input power during the coating of the substrate. Both types of polyterpenol coatings displayed a surface skewness $\left(R_{\text {skw }}\right)$ of approximately or just above 0 and coefficient of kurtosis $\left(R_{\mathrm{kur}}\right)$ values of $\sim 3$, i.e., the $R_{\mathrm{skw}}$ values describe a proportionate number of peaks and valleys pertaining to the polyterpenol surfaces; and the $R_{\text {kur }}$ values signify the surfaces with well spread height distribution $[35,36]$.

Since the attachment of bacterial cells can be influenced by surface morphology of the substrate both on the nanometer and micrometer scale, for each sample type, the roughness data was estimated separately from $1 \mu \mathrm{m} \times 1 \mu \mathrm{m}$ and $10 \mu \mathrm{m} \times 10 \mu \mathrm{m}$ scanning areas, and the respective parameters were 
compared. For polyterpenol films deposited at $10 \mathrm{~W}$, the value for the average $\left(R_{\mathrm{a}}\right)$ roughness estimated using $10 \mu \mathrm{m} \times 10 \mu \mathrm{m}$ scanning data was approximately 5.25 times higher compared to $R_{\mathrm{a}}$ value obtained from $1 \mu \mathrm{m} \times 1 \mu \mathrm{m}$ scans. At $1.58 \mathrm{~nm}$, the RMS $\left(R_{\mathrm{q}}\right)$ roughness was also $\sim 5$ times higher when estimated from $10 \mu \mathrm{m} \times 10 \mu \mathrm{m}$ scanning area than that determined using the data from $1 \mu \mathrm{m} \times 1 \mu \mathrm{m}$ scans, at $0.32 \mathrm{~nm}$. The maximum peak height $\left(R_{\max }\right)$ surface parameter was also 7 times higher when inferred using $10 \mu \mathrm{m} \times 10 \mu \mathrm{m}$, at $17.5 \mathrm{~nm}$, compared to $2.25 \mathrm{~nm}$ attained from $1 \mu \mathrm{m} \times 1 \mu \mathrm{m}$ scans. Although to a lesser extent, similar variation in roughness values obtained from $1 \mu \mathrm{m} \times 1 \mu \mathrm{m}$ and $10 \mu \mathrm{m} \times 10 \mu \mathrm{m}$ scanning areas were observed for polyterpenol films fabricated at $25 \mathrm{~W}$, with the values calculated from larger scanning areas $\sim 1.8$ and 2.4 times higher in the case of average $\left(R_{\mathrm{a}}\right)$ and $\mathrm{RMS}\left(R_{\mathrm{q}}\right)$ roughness, respectively, and 2.9 times higher for maximum peak height $\left(R_{\max }\right)$ compared to those estimated from $1 \mu \mathrm{m} \times 1 \mu \mathrm{m}$ scans. For both types of polyterpenol coating, the difference between surface skewness $\left(R_{\text {skw }}\right)$ values from two scan sizes confirmed that over larger scanning areas, the chance of encountering a deep valley relative to the mean line is higher when compared to $1 \mu \mathrm{m} \times 1 \mu \mathrm{m}$ scanning area. These findings indicate that polyterpenol films are smooth at the sub-nanometer scale.

For unmodified glass substrates, the values of average $\left(R_{\mathrm{a}}\right)$ and RMS $\left(R_{\mathrm{q}}\right)$ roughness, and the maximum peak height $\left(R_{\max }\right)$ were determined to be $\sim 3.6-4.9$ times higher when collected over larger scanning area of $10 \mu \mathrm{m} \times 10 \mu \mathrm{m}$ compared to those of $1 \mu \mathrm{m} \times 1 \mu \mathrm{m}$ area. Notably, both the coefficient of kurtosis $\left(R_{\text {kur }}\right)$ and surface skewness $\left(R_{\text {skw }}\right)$ were $\sim 4$ and 9 times lower, respectively, when calculated using data from the $10 \mu \mathrm{m} \times 10 \mu \mathrm{m}$ scan area than the respective $R_{\mathrm{kur}}$ and $R_{\mathrm{skw}}$ values from the $1 \mu \mathrm{m} \times 1 \mu \mathrm{m}$ data. At 0.34 for $10 \mu \mathrm{m} \times 10 \mu \mathrm{m}$ scan, the smaller value of surface skewness $\left(R_{\mathrm{skw}}\right)$ indicates that over larger scanned areas, the height distribution is more uniform, with approximately equal number of high peaks to deep valleys. Similarly, the lower kurtosis $\left(R_{\text {kur }}\right)$ coefficient over an increased sampling area indicates that on this scale, the roughness profile of the surface has less high peaks and low valleys [36], probably due to the lower resolution of the scan which may not allow for the detection of finer peaks and valleys.

The application of the polymer coating resulted in a significant increase in the substrate surface hydrophobicity, with the water contact angle increasing from $8^{\circ}$ to $63^{\circ}$ and $69^{\circ}$ on the $10 \mathrm{~W}$ and $25 \mathrm{~W}$ polyterpenol coatings, respectively. The surface hydrophobicity/hydrophilicity and surface charge before and after the application of the polymeric coating are summarized in Table 1. Independent of deposition power, application of the coating statistically significantly affected the contact angle values for all three probing liquid $(p<0.05)$. Among polyterpenol samples, the difference was significant only in the case of water, but not for ethylene glycol or diiodomethane solvents. The dispersive component of the surface tension $\gamma^{\mathrm{LW}}$ was not changed significantly by the application of the thin film coating, whilst the polar $\gamma^{\mathrm{AB}}$ component increased from $1.5 \mathrm{~mJ} / \mathrm{m}^{2}$ for the unmodified glass substrate to $9.3 \mathrm{~mJ} / \mathrm{m}^{2}$ and $5.4 \mathrm{~mJ} / \mathrm{m}^{2}$ for the $10 \mathrm{~W}$ and $25 \mathrm{~W}$ samples, respectively. All surfaces were identified as monopolar, with pronounced electron-donating capacity and negligible electron-accepting fraction $\gamma^{+}$. Total surface tension values remained relatively similar for all types of surfaces, ranging from $40 \mathrm{~mJ} \mathrm{~m}^{-2}$ to $50 \mathrm{~mJ} \mathrm{~m}^{-2}$ for unmodified and coated substrates, respectively.

An analysis of the surface chemistry of the native and coated substrates using X-ray photoelectron spectroscopy (XPS) revealed that appreciable differences existed between the surface chemical characteristics of these substrates, as summarized in Table 2, where the relative concentration refers to 
the assignment of the element to a particular binding state (e.g., in $10 \mathrm{~W}$ sample, $81 \%$ of $\mathrm{O}$ is in $\mathrm{C}-\mathrm{O} / \mathrm{C}=\mathrm{O} / \mathrm{Si}-\mathrm{O}$, and $19 \%$ is in ${ }^{*} \mathrm{O}-\mathrm{C}=\mathrm{O}$ ). In the case of the unmodified glass, the SEM analysis revealed the presence of predominantly $\mathrm{Si}$ and $\mathrm{O}$, which is expected of glass surfaces. Examination of the $\mathrm{C}$ 1s high-resolution spectra indicated the existence of hydrocarbons $(\mathrm{C}-\mathrm{C}, \mathrm{C}-\mathrm{H})$, carbon singly bonded to oxygen or nitrogen $(\mathrm{C}-\mathrm{O}, \mathrm{C}-\mathrm{N})$, carbon doubly bonded to oxygen $(\mathrm{C}=\mathrm{O})$ and carbonate species $\left(\mathrm{CO}_{3}\right)$. Modification of the glass substrate using polyterpenol resulted in a significant increase of carbon available on the surface of the substrate. Furthermore, polyterpenol coatings deposited at different $\mathrm{RF}$ input power differed in terms of their $\mathrm{C}$ and $\mathrm{O}$ ratio, with films fabricated at $10 \mathrm{~W}$ characterized with lower oxygen $(17.2 \%$ vs. $27.5 \%)$ and higher carbon (80\% vs. $68.4 \%)$ fractions compared to polymers deposited at $25 \mathrm{~W}$. Silicon was present in small quantity $(\sim 3 \%)$ on both types of polyterpenol films, whilst some $\mathrm{Na}(0.4 \%)$ and $\mathrm{N}(1.0 \%)$ traces were detected on $25 \mathrm{~W}$ samples.

Table 2. Relative contributions of different chemical states on the surfaces of polyterpenol thin films assigned to the X-ray photoelectron spectroscopy (XPS) peaks.

\begin{tabular}{|c|c|c|c|c|c|c|c|}
\hline \multirow[b]{2}{*}{ Element/transition } & \multirow[b]{2}{*}{ Assignment } & \multicolumn{2}{|c|}{ Unmodified substrate } & \multicolumn{2}{|c|}{ Polyterpenol $10 \mathrm{~W}$} & \multicolumn{2}{|c|}{ Polyterpenol 25 W } \\
\hline & & $\begin{array}{c}\text { Binding } \\
\text { energy }(\mathrm{eV})\end{array}$ & $\begin{array}{c}\text { Relative } \\
\text { Conc. }(\%)\end{array}$ & $\begin{array}{c}\text { Binding } \\
\text { energy }(e V)\end{array}$ & $\begin{array}{c}\text { Relative } \\
\text { Conc. }(\%) \\
\end{array}$ & $\begin{array}{c}\text { Binding } \\
\text { energy }(\mathrm{eV})\end{array}$ & $\begin{array}{c}\text { Relative } \\
\text { Conc. }(\%) \\
\end{array}$ \\
\hline \multirow[t]{2}{*}{$\mathrm{O} 1 \mathrm{~s}$} & $\mathrm{C}--\mathrm{O} / \mathrm{C}=\mathrm{O} / \mathrm{Si}--\mathrm{O}$ & & & 532.5 & 81 & 532.2 & 70 \\
\hline & $* \mathrm{O}-\mathrm{-C}=\mathrm{O}$ & & & 533.5 & 19 & 533.3 & 30 \\
\hline \multirow[t]{2}{*}{ N1s } & $\mathrm{C}-\mathrm{N}$ & 400.5 & 100 & & & 400.0 & 74 \\
\hline & $\mathrm{C}-\mathrm{N}^{+}$ & & & & & 401.9 & 26 \\
\hline $\mathrm{Ca} 2 \mathrm{p}$ & $\mathrm{Ca}^{2+}$ & 347.9 & 100 & & & & \\
\hline \multirow[t]{4}{*}{$\mathrm{C} 1 \mathrm{~s}$} & $\mathrm{C}-\mathrm{C}, \mathrm{C}-\mathrm{H}$ & 285.0 & 80 & 285.0 & 77 & 284.9 & 60 \\
\hline & $\mathrm{C}-\mathrm{O}, \mathrm{C}-\mathrm{N}$ & 286.5 & 12 & 286.5 & 15 & 286.5 & 21 \\
\hline & $\mathrm{CO}_{3}$ & 289.3 & 4 & 289.2 & 2 & 289.1 & 8 \\
\hline & $\mathrm{C}=\mathrm{O}$ & 288.1 & 4 & 287.8 & 6 & 287.9 & 12 \\
\hline \multirow[t]{2}{*}{$\mathrm{Si} 2 \mathrm{p}$} & $\mathrm{SiO}_{2}$ & 103.3 & 100 & & & & \\
\hline & $\mathrm{Si}-\mathrm{O}$ & & & 102.2 & 100 & 102.0 & 100 \\
\hline
\end{tabular}

\subsection{Bacterial Surface Properties}

In addition to the surface properties of the substrates, bacterial surface characteristics such as hydrophobicity and surface charge were investigated. The $P$. aeruginosa cells have been characterized as moderately hydrophilic, with a water contact angle of $\sim 43^{\circ}$, whilst $S$. aureus cells exhibited more hydrophobic characteristics, with a water contact angle of $\sim 72^{\circ}$, most likely due to the presence of highly negatively charged and hydrophobic teichoic and lipoteichoic acid sites in the $S$. aureus cell walls $[37,38]$. The zeta potential of the bacterial cells $(\zeta)$ was estimated to be $-14.4 \pm 0.7 \mathrm{mV}$ and $-35.2 \pm 1.0 \mathrm{mV}$ for $P$. aeruginosa and $S$. aureus, respectively. These results were used to deduce the cell surface charge characteristics of the studied microorganisms. The $S$. aureus cells were more electronegative compared to those of $P$. aeruginosa, with the respective mobilities in the range of $-2(\mu \mathrm{m} / \mathrm{s}) /(\mathrm{V} / \mathrm{cm})$ and $-1.12(\mu \mathrm{m} / \mathrm{s}) /(\mathrm{V} / \mathrm{cm})$. Negative charge is common for the majority of microbial cell surfaces, with the values given above being consistent with previously published results for these two bacterial species [40,41]. Given the estimated surface wettability and surface charge of 
the $P$. aeruginosa and $S$. aureus bacterial cells, these microorganisms may not have a strong affinity for the highly hydrophilic surface of the unmodified glass substrate [18].

\subsection{Bacterial Attachment}

The attachment patterns of $P$. aeruginosa and $S$. aureus cells after $18 \mathrm{~h}$ incubation were examined by means of high-resolution SEM and confocal scanning laser microscope (CLSM) imaging, followed by statistical analysis. The attachment patterns of the two bacterial species were seen to be markedly different, preserving, however, a similar response on two types of polyterpenol film, as shown in Figure 2 and reported in [34]. Furthermore, inspection of the SEM images demonstrated notable differences in the cell morphology, production of EPSs, and the numbers of bacterial cells attaching to the three types of substrates, namely the unmodified glass, polymer film fabricated at $10 \mathrm{~W}$ and the coating deposited at $25 \mathrm{~W}$ input power.

Figure 2. Representative S. aureus attachment patterns on the unmodified (left panel) glass, modified with $10 \mathrm{~W}$ (middle panel), and $25 \mathrm{~W}$ (right panel) polyterpenol thin coating after $18 \mathrm{~h}$ incubation. Images on the top collected using SEM; (inset) SEM images showing typical cell morphologies of the attached microorganisms. Confocal scanning laser microscopy (CSLM) images (bottom) visualize viable cells stained green and dead cells stained red with BacLight ${ }^{\circledR}$ Dead/Live Kit (Invitrogen), scanned areas of approximately $126 \mu \mathrm{m} \times 126 \mu \mathrm{m}$.
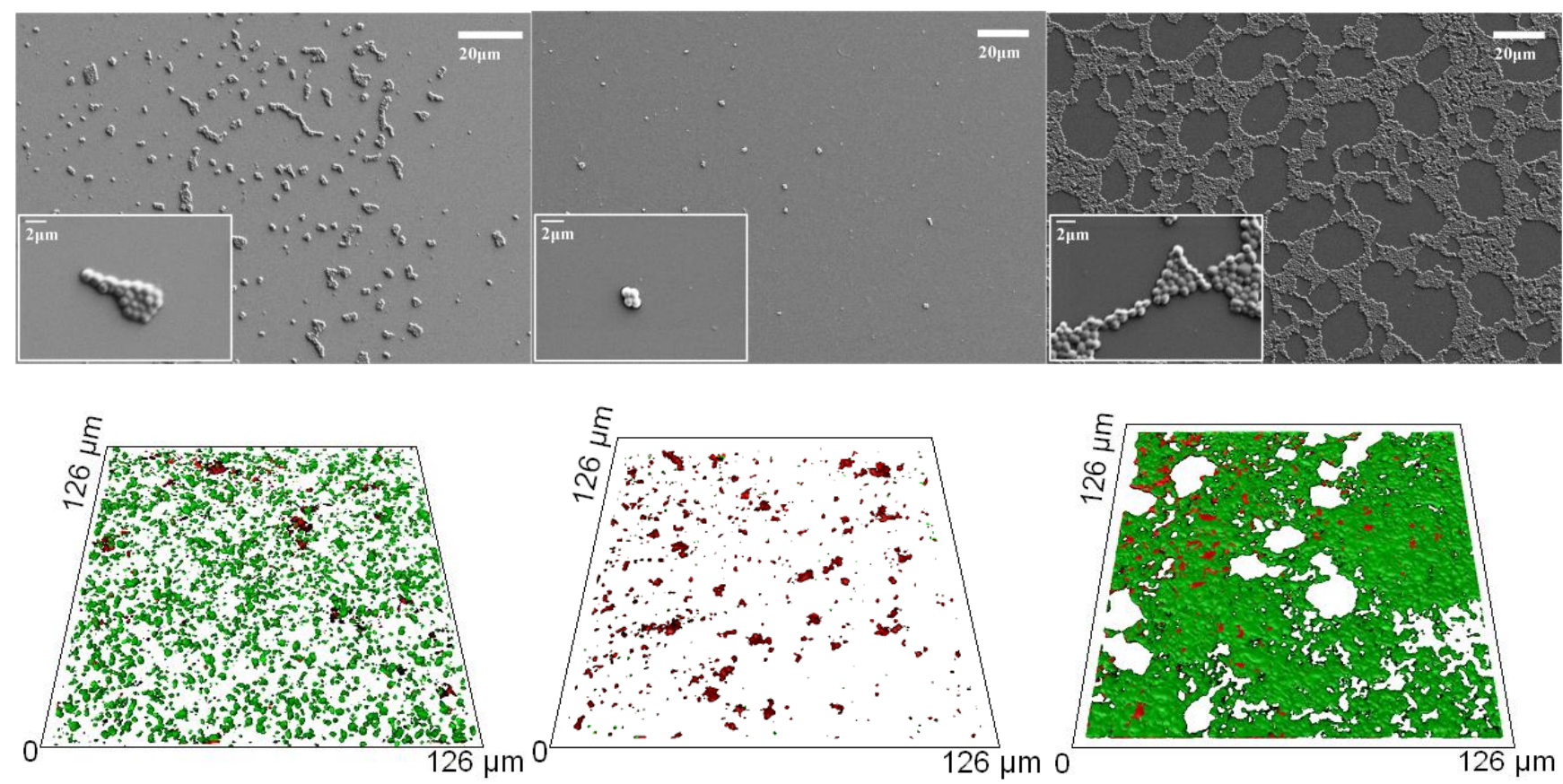

Overall, the number of cells attached to the surface modified with $25 \mathrm{~W}$ polyterpenol thin films was found to be significantly higher when compared to the number of cells attaching to the unmodified glass and $10 \mathrm{~W}$ polyterpenol surfaces, despite the fact that surfaces of polyterpenol thin films fabricated under $10 \mathrm{~W}$ RF were smoother on nanometer scale than those of the unmodified glass (Figures 2 and 3). This is due to the antibacterial inhibitory properties exhibited by these surfaces, resulting in lower amounts of bacterial attachment. In the case of S. aureus, however, the SEM images 
clearly showed an increase in the number of attached cells for substrates modified with $25 \mathrm{~W}$ polyterpenol coating. Furthermore, the distribution of $S$. aureus cells on the surface changed from irregular to more uniform for $10 \mathrm{~W}$ and $25 \mathrm{~W}$ samples, respectively. Morphological examination of $S$. aureus revealed slight differences in cell size on the sample surfaces, with larger $\sim 0.8-1 \mu \mathrm{m}$ cells appearing on the surface of the unmodified glass and $25 \mathrm{~W}$ samples as opposed to the $\sim 0.6 \mu \mathrm{m}$ cells adhered to the surface of the $10 \mathrm{~W}$ polyterpenol coatings.

Figure 3. Quantification of S. aureus biovolume and average biofilm thickness on the surfaces of the unmodified glass and polymer coated substrata.

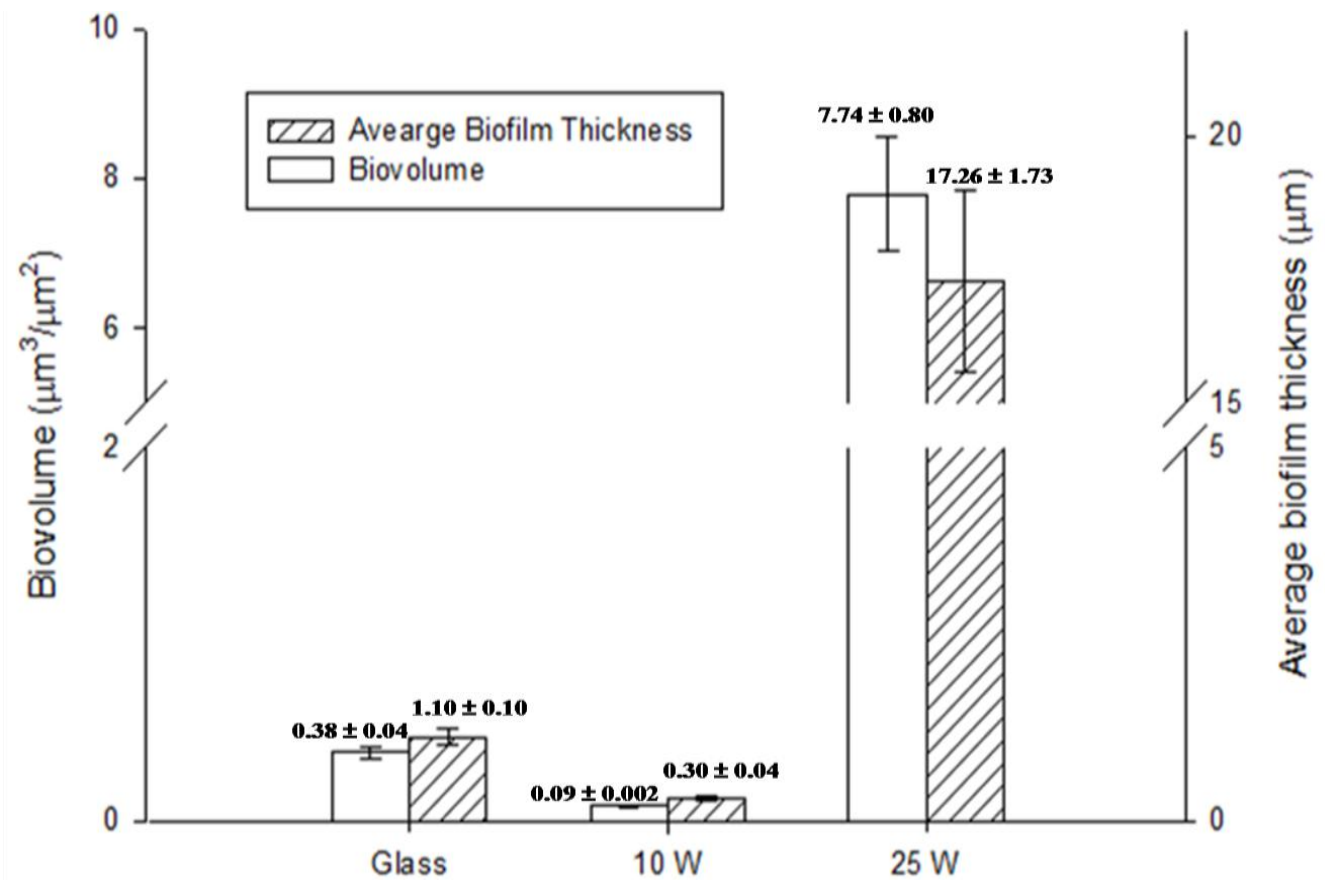

The amount of EPS produced by $S$. aureus cells was not significant for all of the samples examined, as confirmed by CLSM. The S. aureus attachment pattern on the polymer was further investigated using CLSM imaging, with the results confirming the observations made from the SEM data. The CLSM images of live cells (stained red with SYTO ${ }^{\circledR} 17$ Red) and EPS (stained green with concanavalin A 488) produced by cells attached to the unmodified and polymer coated surfaces were statistically analyzed using the COMSTAT package. Figure 3 shows the biovolume and average biofilm thickness of $S$. aureus on the surfaces of the unmodified glass and polymer coated substrates, calculated using the COMSTAT software. An error of approximately $10-15 \%$ in the density values obtained for these samples can be attributed to the local variability in the surface coverage. A SEM analysis of the glass surface used as an experimental control revealed an even distribution of the attached cells across the surface of the substrate, with the attachment response being somewhat similar to that obtained for the surfaces of the $10 \mathrm{~W}$ deposition samples. However, the 3D CLSM imaging revealed a much higher number of cells attached to the glass surface compared to that of the $10 \mathrm{~W}$ coating, with an average biofilm thickness being approximately 4 times larger on glass than that on the $10 \mathrm{~W}$ polyterpenol films. The $S$. aureus cells exhibited a preference for attachment onto the $25 \mathrm{~W}$ polymer modified surface as evident from the SEM and 3D CLSM images. Analysis of CLSM images 
(Figure 2) clearly indicated that above $90 \%$ of $S$. aureus cells retained on the surfaces of $10 \mathrm{~W}$ substrata were non-viable, in contrast to $S$. aureus cells retained on the unmodified glass and $25 \mathrm{~W}$ substrata.

These results for $S$. aureus are consistent with previously reported observations for $P$. aeruginosa [34], where the number of $P$. aeruginosa cells attaching to the $10 \mathrm{~W}$ polymer surface was found to be significantly lower than that obtained on the glass surfaces, with an average biofilm thickness of $0.47 \pm 0.02 \mu \mathrm{m}$ compared to thicknesses of $1.14 \pm 0.22 \mu \mathrm{m}$ and $23.09 \pm 2.15 \mu \mathrm{m}$ observed on glass and $25 \mathrm{~W}$ substrates, respectively. Furthermore, $P$. aeruginosa cells were found to be significantly larger and slightly thinner $(\sim 1.7-2 \mu \mathrm{m}$ long and $\sim 0.5-0.6 \mu \mathrm{m}$ wide) when attached to the $25 \mathrm{~W}$ substrate and the glass reference sample compared to those attached to the $10 \mathrm{~W}$ samples ( $\sim 1.2 \mu \mathrm{m}$ long and $\sim 0.7 \mu \mathrm{m}$ wide). Similarly, the cells produced significantly more EPS when attached to the glass and $25 \mathrm{~W}$ substrates, with the biovolume increasing from $0.09 \pm 0.005 \mu \mathrm{m}^{2} / \mu \mathrm{m}^{3}$ on the $10 \mathrm{~W}$ surfaces to $0.61 \pm 0.09 \mu \mathrm{m}^{2} / \mu \mathrm{m}^{3}$ and $4.34 \pm 0.39 \mu \mathrm{m}^{2} / \mu \mathrm{m}^{3}$ on the glass and nanosmooth surfaces of $25 \mathrm{~W}$ samples, respectively.

\section{Discussion}

Our results showed that the presence of the polyterpenol thin films significantly altered the surface properties of the glass substrates, which resulted in a notable change in the adhesion behavior of both $P$. aeruginosa and $S$. aureus cells. The difference in surface architecture was reflected in the surface roughness parameters of polyterpenol coatings applied under different deposition power. This was attributed to the degree of monomer fragmentation resulting from the increased intensity of the plasma field. The lower deposition rate and higher substrate temperature associated with the increased RF power conditions allowed for a faster relaxation of film fragments within the growth region prior to deposition of the next layer of the film, resulting in a smoother surface [22]. This observation is clearly supported by the notable differences in roughness parameters of the two polyterpenol surfaces examined, particularly when the data from $10 \mu \mathrm{m} \times 10 \mu \mathrm{m}$ scanning area sizes are compared. The higher peaks observed on the surfaces of the $10 \mathrm{~W}$ samples can be also explained by the presence of large fragments of terpinen-4-ol molecule that are loosely bound to the surface of the polymer matrix.

Modification of the surface properties using polyterpenol not only altered the surface architecture, but also the surface chemistry. The combined effect of these two parameters can strongly influence the extent of bacterial adhesion and proliferation while preserving the material properties inherent to the substrate, such as the mechanical properties [39]. Alterations of the functional groups present on the surface of the substrate change the surface hydrophobicity and surface energy. These parameters not only directly affect the interactions between the cells and the substrate, but also the manner in which the surface interacts with its immediate environment, such as the liquid medium [40]. Previously published $S$. aureus adhesion studies showed that bacterial cells tended to attach more effectively to surfaces bearing carboxylic and methyl functional groups than those containing hydroxyl functionality [41]. Other studies reported a reduction in bacterial adhesion for negatively charged poly(methyl methacrylate)/acrylic acid functional groups, whilst the presence of positively charged methyl methacrylate/dimethylaminoethyl methacrylate groups resulted in an increased level of bacterial cell attachment [14]. In this study, the modification of the surface chemistry of the substrates resulted in a significant increase in the amount of carbon available on the surface. The higher oxygen 
concentration observed in the case of the $25 \mathrm{~W}$ polymer films can be attributed to the oxidation of the top layer of the film, which is part of the post-degradation ageing reaction occurring in the film. Due to the nature of the fabrication process, films manufactured at higher input energy tend to contain a higher number of radicals compared to those deposited at lower power settings, as the lower power conditions favor the preservation of original molecular structure of the monomer precursor [31].

Comparison of the attachment preferences of $S$. aureus to unmodified glass surfaces and $25 \mathrm{~W}$ polymer coated substrates showed that the presence of the polyterpenol film resulted in a significant increase in the number of the attached bacterial cells, their size and the quantity of EPS these cells produced. $P$. aeruginosa was also found to attach more readily to the $25 \mathrm{~W}$ samples compared to the unmodified glass substrates, a behavior similar to that previously reported for $P$. aeruginosa on topographically dissimilar glass surfaces and on polyterpenol samples [34,42]. There is much debate and controversies concerning the extent to which surface free energy and its polar component affect bacterial adhesion $[43,44]$. In the case of $S$. aureus, the thermodynamically predicted preference of hydrophobic cells for hydrophobic substrates can partially account for the reduced cell adhesion to the more hydrophilic surface of the unmodified glass substrate, as reported elsewhere [45]. The $25 \mathrm{~W}$ polymer layer is smooth on the sub-nano-scale roughness level compared to unmodified substrate; therefore the current "attachment point" theory [46-47] that suggests that bacterial cells prefer microscopic surface irregularities as the starting point for their attachment as these provide shelter from unfavorable environmental influences clearly also cannot explain the attachment behavior. Our recent studies found that nano-scale surface roughness may have a notable effect on bacterial attachment and adhesion, with nano-scale fluctuations in roughness exerting a significant influence on the cellular response to certain surfaces $[18,42,48]$. The results presented here show that a higher number of bacterial cells were able to colonize the nano-smooth $25 \mathrm{~W}$ polymer coated substrates, whereas less smooth, unmodified glass substrates sustained a significantly lower level of cellular attachment. This adhesion tendency was observed for both strains used in this study, regardless of their taxonomic affiliation and their cell surface characteristics. Further studies on polyterpenol coatings fabricated at even higher RF powers showed a similar trend [49].

Glass substrates modified with a $10 \mathrm{~W}$ polyterpenol coating exhibited the least number of bacterial cells adhering to the surface. In its monomer form, terpinen-4-ol has been characterized as a nonspecific membrane active biocide that possesses adequate hydrophilicity to diffuse through liquid medium to the bacterial cytoplasmic membrane and hydrophobicity necessary to diffuse through the bacterial cytoplasmic membrane [28], where it accumulates causing a loss of membrane integrity [50]. Previous studies have demonstrated that it is possible to preserve certain functionalities and hence the biological activity of terpinen-4-ol in polyterpenol thin films by using relatively low deposition power conditions $[33,34]$. Hence, the significant reduction in the attachment of bacterial cells observed on these surfaces could be due to the preservation of chemical activity rather than the reduction in the surface irregularities or an increase in the hydrophobicity of the surface compared to the unmodified substrate.

\section{Experimental}

Modification of the surface of glass substrates was achieved using radio frequency plasma enhanced chemical vapor deposition (RF-PECVD) of a thin layer of polymer coating using terpinen-4-ol 
(Australian Botanical Products, Ltd.) as a precursor. The detailed account of the experimental set-up and deposition procedure is outlined elsewhere [31]. Briefly, the RF energy (13.56 MHz) was delivered into a custom-designed glass deposition chamber by means of two capacitively coupled copper electrodes. Glass substrates (BioLab Scientific, Ltd.) were pre-washed in a 1:5 solution of Extran and distilled water, ultrasonically cleaned using distilled water heated to $50{ }^{\circ} \mathrm{C}$ for $30 \mathrm{~min}$, rinsed with propan-2-ol and dried. Cleaned substrates were then placed into the deposition reactor, which was then evacuated to 200 mTorr, flushed with argon for 1 min to ensure that the substrates possessed an oxygen-free surface. The chamber was then evacuated to achieve a pressure of 50 mTorr. The terpinen-4-ol vapor was released gradually into the chamber and the glow was maintained by controlling the monomer flow [32]. Deposition was performed in two stages at room temperature and pressure of 200 mTorr. First, to improve the strength of adhesion between the coating and the substrate, a $100 \mathrm{~nm}$ layer of polyterpenol thin film was deposited using input power of $75 \mathrm{~W}$. Then, a functional coating was deposited from terpinen-4-ol under $10 \mathrm{~W}$ or $25 \mathrm{~W}$ RF power for 10 min to achieve films of approximately the same thickness.

The roughness parameters of both the native and coated glass surfaces were quantitatively analyzed using an atomic force microscope (AFM) (NT-MDT) in semi-contact (tapping) mode, using (NSC05, NT-MDT) cantilevers with a spring constant of $11 \mathrm{~N} / \mathrm{m}$, tip radius of curvature of $10 \mathrm{~nm}$, aspect ratio of 10:1 and resonance frequency of $150 \mathrm{KHz}$. 3-D interactive visualization and statistical approximation was used to analyze the topographic profiles of the surfaces. Scanning was performed perpendicular to the axis of the cantilever at a rate of typically $1 \mathrm{~Hz}$, with the scan areas of $1 \mu \mathrm{m} \times 1 \mu \mathrm{m}$ and $10 \mu \mathrm{m} \times 10 \mu \mathrm{m}$. At least five samples for the surfaces of each condition have been investigated.

In addition to the surface morphology, surface chemical characteristics were also determined. The chemical composition of the surface before and after coating was analyzed by means of X-ray photoelectron spectroscopy (XPS). XPS was performed using an Axis Ultra spectrometer (Kratos Analytical Ltd., UK), equipped with a monochromatic X-ray source (Al $\mathrm{K} \alpha, \mathrm{h} v=1,486.6 \mathrm{eV})$ operating at $150 \mathrm{~W}$, as described elsewhere [34]. Using the Kratos Vision II software, peaks in the high-resolution regions of spectra were fitted with synthetic Gaussian-Lorentzian components. Surface wettability was determined from contact angle measurements using (KSV 101) employing the sessile drop method [51-54].

Prior to each experiment, a fresh bacterial suspension of $\mathrm{OD}_{600 \mathrm{~nm}}=0.3$ was prepared from P. aeruginosa ATCC 9025 and S. aureus CIP 68.5 cells grown in nutrient broth (Oxoid) at room temperature $\left(\sim 22{ }^{\circ} \mathrm{C}\right)$ for $24 \mathrm{~h}$. A portion of $100 \mu \mathrm{L}$ of bacterial suspension was deposited onto the surface of each sample (in triplicate). Sterile nutrient broth $(100 \mu \mathrm{L})$ was used as a negative control. After incubation for $18 \mathrm{~h}$ at $37{ }^{\circ} \mathrm{C}$, all of the samples were gently washed with copious amounts deionized water and left to dry at room temperature for $45 \mathrm{~min}$ at 55\% humidity. A FeSEM-ZEISS SUPRA 40VP was used to obtain high-resolution images of the bacterial cells. Just before imaging, all slides were gold coated in order to achieve better conductivity. Separately, concanavalin A Alexa 488 dye (Molecular Probes Inc.) was used to label the extracellular polysaccharide (EPS) produced by the bacteria while attaching to the surfaces. After incubation, all samples were washed with sterilized nanopure water and carefully stored until being analyzed at room temperature $\left(\sim 22{ }^{\circ} \mathrm{C}\right)$. The confocal scanning laser microscope (CSLM) Olympus Fluoview FV1000 Spectroscopic Confocal System was used [34]. Excitation and emission wavelengths for concanavalin A are $495 \mathrm{~nm}$ and $519 \mathrm{~nm}$, respectively. 
Also, viability of attached bacterial cells was determined using Live/Dead ${ }^{\circledR}$ BacLight $^{\mathrm{TM}}$ Viability kit (L7007, Invitrogen). The staining was carried out according to the manufacturer's protocol.

Using a First Ten Angstroms (FTA200) instrument, sessile drop contact angle measurements were performed on the lawns of bacterial cells to estimate the surface wettability of the bacterial samples. Bacterial cells were washed three times and then suspended in a buffer (OD450 $=0.4$ ). A bacterial lawn was formed by depositing the bacterial suspension onto cellulose acetate membrane filters (Sartorius, pore diameter $0.2 \mu \mathrm{m}$ ), which were then sufficiently dried at ambient temperature prior to measurement of the contact angle to reach "plateau state", whereby stable water contact angles can be measured over time. The contact angle of the water droplets deposited onto the bacterial lawns was recorded using a charge-coupled device (CCD) camera. Images were digitally saved and analyzed using the image analysis software (v 1.961; Folio Instruments Inc.).

For the electrophoretic mobility measured using a zeta potential analyzer (ZetaPALS, Brookhaven Instruments Corp.), the bacterial cells were harvested by centrifugation for $5 \mathrm{~min}$ at 5,000 rpm after $24 \mathrm{~h}$ of incubation. Harvested cell pellet was re-suspended in $10 \mathrm{mM}$ potassium chloride $(\mathrm{KCl})$ followed by further washing and centrifugation. This step was repeated four times and finally the cells were re-suspended in $10 \mathrm{mM} \mathrm{KCl}$ solution to $\mathrm{OD}(600 \mathrm{~nm})=1$. The resultant solution of bacterial cells was further diluted 1,000 times in $5 \mathrm{~mL}$ of $10 \mathrm{mM} \mathrm{KCl}$. Measurements were conducted in electric field $2.5 \mathrm{~V} \mathrm{~cm}^{-1}$ and $2 \mathrm{~Hz}$. All measurements were done in triplicate and for each sample the final EPM quoted represented the average of five successive ZetaPALS readings, each of which consisted of 14 cycles per run.

\section{Conclusions}

High resolution AFM studies showed that application of a polyterpenol coating significantly altered the surface topography of the substrates, decreasing the substrate average surface roughness $\left(R_{\mathrm{a}}\right)$ from approximately $0.4 \mathrm{~nm}$ to $0.25 \mathrm{~nm}$ and $0.13 \mathrm{~nm}$ for $10 \mathrm{~W}$ and $25 \mathrm{~W}$ polyterpenol coatings, respectively (scan size $1 \mu \mathrm{m} \times 1 \mu \mathrm{m}$ ). A statistical analysis of the roughness parameters showed that there was a statistically significant difference in the surfaces roughness parameters for each of the coated and unmodified substrates used in this study. The extent of bacterial attachment and EPS production was then analyzed using SEM and CSLM. The CSLM and SEM analyses clearly demonstrated that $S$. aureus and $P$. aeruginosa presented notably different patterns of attachment onto surfaces of polyterpenol thin films fabricated under the two conditions. The smoothon the scale of nanometers $25 \mathrm{~W}$ polyterpenol coating resulted in enhanced attachment and adherence of two taxonomically different bacterial strains, the behavior previously described in our recent works. However, bacterial attachment can be further controlled by changing the surface chemical functionality, by, for example, coating the substrate with terpinen-4-ol, a compound with known bacterial inhibitory activity. Despite being characterized as smoother on a nanometer scale than glass surfaces, the degree of attachment, EPS production, and cell proliferation on the polyterpenol thin films fabricated under $10 \mathrm{~W}$ was found to be greatly reduced compared to that obtained on the unmodified surface or on the polyterpenol thin films fabricated under $25 \mathrm{~W}$ deposition power conditions. The added advantages of this coating include uniform coverage, good adhesion to the substrate, and film stability. Furthermore, the antibacterial efficacy is based on the presence of a natural antimicrobial compound with no use of antibiotics. Thus, 
this work suggests that such an antimicrobial and antifouling coating could be effectively integrated into medical and other clinically relevant devices to prevent bacterial growth, thus minimizing bacteria-associated adverse host responses.

\section{Acknowledgements}

This study was supported in part by Advanced Manufacturing Co-operative Research Centre (AMCRC). K. B. is a recipient of Australian Postgraduate Award (APA) and Australian Institute of Nuclear Science and Engineering Postgraduate Award (AINSE PGRA); K. B. is grateful to the funding and support received from the Rural Industry Research and Development Corporation (RIRDC) and the Department of Agriculture, Fisheries and Forestry of Australia (DAFF) as a part of Science and Innovation Award for Young People in Agriculture, Fisheries and Forestry. V. K. T. is a recipient of Swinburne University Postgraduate Research Award (SUPRA) award.

\section{References}

1. Hanssen, A.D. Managing the infected knee: As good as it gets. J. Arthroplasty 2002, 17, 98-101.

2. Montanaro, L.; Campoccia, D.; Arciola, C.R. Advancements in molecular epidemiology of implant infections and future perspectives. Biomaterials 2007, 28, 5155-5168.

3. Liu, X.; Chu, P.K.; Ding, C. Surface modification of titanium, titanium alloys, and related materials for biomedical applications. Mater. Sci. Eng. R Rep. 2004, 47, 49-121.

4. Stobie, N.; Duffy, B.; McCormack, D.E.; Colreavy, J.; Hidalgo, M.; McHale, P.; Hinder, S.J. Prevention of Staphylococcus epidermidis biofilm formation using a low-temperature processed silver-doped phenyltriethoxysilane sol-gel coating. Biomaterials 2008, 29, 963-969.

5. Subbiahdoss, G.; Kuijer, R.; Grijpma, D.W.; van der Mei, H.C.; Busscher, H.J. Microbial biofilm growth vs. tissue integration: "The race for the surface" experimentally studied. Acta Biomater. 2009, 5, 1399-1404.

6. Gottenbos, B.; van der Mei, H.C.; Klatter, F.; Nieuwenhuis, P.; Busscher, H.J. In vitro and in vivo antimicrobial activity of covalently coupled quaternary ammonium silane coatings on silicone rubber. Biomaterials 2002, 23, 1417-1423.

7 Mayer, C.; Moritz, R.; Kirschner, C.; Borchard, W.; Maibaum, R.; Wingender, J.; Flemming, H.-C. The role of intermolecular interactions: Studies on model systems for bacterial biofilms. Int. J. Biol. Macromol. 1999, 26, 3-16.

8. Bos, R.; van der Mei, H.C.; Busscher, H.J. Physico-chemistry of initial microbial adhesive interactions-Its mechanisms and methods for study. FEMS Microbiol. Rev. 1999, 23, 179-229.

9. An, Y.H.; Friedman, R.J.; Draughn, R.A.; Smith, E.A.; Nicholson, J.H.; John, J.F. Rapid quantification of staphylococci adhered to titanium surfaces using image analyzed epifluorescence microscopy. J. Microbiol. Method. 1995, 24, 29-40.

10. Whitehead, K.A.; Colligon, J.; Verran, J. Retention of microbial cells in substratum surface features of micrometer and sub-micrometer dimensions. Colloid. Surf. B 2005, 41, 129-138.

11. Diaz, C.; Cortizo, M.C.; Schilardi, P.L.; de Saravia, S.G.G.; de Mele, M.A.F.L. Influence of the nano-micro structure of the surface on bacterial adhesion. Mater. Res. 2007, 10, 11-14. 
12. Harris, L.G.; Tosatti, S.; Wieland, M.; Textor, M.; Richards, R.G. Staphylococcus aureus adhesion to titanium oxide surfaces coated with non-functionalized and peptide-functionalized poly(-lysine)-grafted-poly(ethylene glycol) copolymers. Biomaterials 2004, 25, 4135-4148.

13. Scheuerman, T.R.; Camper, A.K.; Hamilton, M.A. Effects of Substratum Topography on Bacterial Adhesion. J. Colloid Interface Sci. 1998, 208, 23-33.

14. Katsikogianni, M.; Missirlis, Y.F. Concise review of mechanisms of bacterial adhesion to biomaterials and of techniques used in estimating bacteria-material interactions. Eur. Cells Mater. 2004, 8, 37-57.

15. Edwards, K.J.; Rutenberg, A.D. Microbial response to surface microtopography: The role of metabolism in localized mineral dissolution. Chem. Geolog. 2001, 180, 19-32.

16. Truong, V.K.; Rundell, S.; Lapovok, R.; Estrin, Y.; Wang, J.Y.; Berndt, C.C.; Barnes, D.G.; Fluke, C.J.; Crawford, R.J.; Ivanova, E.P. Effect of ultrafine-grained titanium surfaces on adhesion of bacteria. Appl. Microbiol. Biotechnol. 2009, 83, 925-937.

17. Mitik-Dineva, N.; Wang, J.; Truong, V.K.; Stoddart, P.; Malherbe, F.; Crawford, R.J.; Ivanova, E.P. Escherichia coli, Pseudomonas aeruginosa and Staphylococcus aureus Attachment Patterns on Glass Surfaces with Nanoscale Roughness. Curr. Microbiol. 2009, 58, 268-273.

18. Mitik-Dineva, N.; Wang, J.; Mocanasu, R.C.; Stoddart, P.R.; Crawford, R.J.; Ivanova, E.P. Impact of nano-topography on bacterial attachment. Biotechnol. J. 2008, 3, 536-544.

19. Ivanova, E.P.; Mitik-Dineva, N.; Wang, J.; Pham, D.K.; Wright, J.P.; Nicolau, D.V.; Mocanasu, R.C.; Crawford, R.J. Staleya guttiformis attachment on poly(tert-butylmethacrylate) polymeric surfaces. Micron 2008, 39, 1197-1204.

20. Biederman, H.; Slavínská, D. Plasma polymer films and their future prospects. Surf. Coating. Technol. 2000, 125, 371-376.

21. Denes, F.S.; Manolache, S. Macromolecular plasma-chemistry: An emerging field of polymer science. Progr. Polym. Sci. 2004, 29, 815-885.

22. Johnston, E.E.; Ratner, B.D. Surface characterization of plasma deposited organic thin films. $J$. Electron Spectrosc. Relat. Phen. 1996, 81, 303-317.

23. Muccini, M. A bright future for organic field-effect transistors. Nat. Mater. 2006, 5, 605-613.

24 Shi, F.F. Recent advances in polymer thin films prepared by plasma polymerization: Synthesis, structural characterization, properties and applications. Surf. Coating. Technol. 1996, 82, 1-15.

25. Yasuda, H. Glow discharge polymerization. J. Polym. Sci. Macromol. Rev. 1981, 16, 199-293.

26. Terada, A.; Yuasa, A.; Kushimoto, T.; Tsuneda, S.; Katakai, A.; Tamada, M. Bacterial adhesion to and viability on positively charged polymer surfaces. Microbiology 2006, 152, 3575-3583.

27. Brady, A.; Loughlin, R.; Gilpin, D.; Kearney, P.; Tunney, M. In vitro activity of tea-tree oil against clinical skin isolates of meticillin-resistant and -sensitive Staphylococcus aureus and coagulase-negative staphylococci growing planktonically and as biofilms. J. Med. Microbiol. 2006, 55, 1375-1380.

28. Loughlin, R.; Gilmore, B.F.; McCarron, P.A.; Tunney, M.M. Comparison of the cidal activity of tea tree oil and terpinen-4-ol against clinical bacterial skin isolates and human fibroblast cells. Lett. Appl. Microbiol. 2008, 46, 428-433. 
29. Mondello, F.; De Bernardis, F.; Girolamo, A.; Cassone, A.; Salvatore, G. In vivo activity of terpinen-4-ol, the main bioactive component of Melaleuca alternifolia Cheel (tea tree) oil against azole-susceptible and -resistant human pathogenic Candida species. BMC Infec. Dis. 2006, 6, 158.

30. Mondello, F.; De Bernardis, F.; Girolamo, A.; Salvatore, G.; Cassone, A. In vitro and in vivo activity of tea tree oil against azole-susceptible and -resistant human pathogenic yeasts. $J$. Antimicrob. Chemother. 2003, 51, 1223-1229.

31. Bazaka, K.; Jacob, M.V. Post-deposition ageing reactions of plasma derived polyterpenol thin films. Polym. Degrad. Stabil. 2010, 95, 1123-1128.

32. Bazaka, K.; Jacob, M.V. Synthesis of radio frequency plasma polymerized non-synthetic Terpinen-4-ol thin films. Mater. Lett. 2009, 63, 1594-1597.

33. Bazaka, K.; Jacob, M.V.; Ivanova, E.P. A study of a retention of antimicrobial activity by plasma polymerized terpinen-4-ol thin films. Mater. Sci. Forum 2010, 654-656, 2261-2264.

34. Bazaka, K.; Jacob, M.V.; Truong, V.K.; Wang, F.; Pushpamali, W.A.; Wang, J.; Ellis, A.; Berndt, C.C.; Crawford, R.J.; Ivanova, E.P. Effect of plasma-enhaced chemical vapour deposition on the retention of antibacterial activity of terpinen-4-ol. Biomacromolecules 2010, 11, 2016-2026.

35. Lamolle, S.F.; Monjo, M.; Rubert, M.; Haugen, H.J.; Lyngstadaas, S.P.; Ellingsen, J.E. The effect of hydrofluoric acid treatment of titanium surface on nanostructural and chemical changes and the growth of MC3T3-E1 cells. Biomaterials 2009, 30, 736-742.

36. Gadelmawla, E.S.; Koura, M.M.; Maksoud, T.M.A.; Elewa, I.M.; Soliman, H.H. Roughness parameters. J. Mater. Process. Technol. 2002, 123, 133-145.

37. Gross, M.; Cramton, S.E.; Gotz, F.; Peschel, A. Key role of teichoic acid net charge in Staphylococcus aureus colonization of artificial surfaces. Infec. Immunity 2001, 69, 3423-3426.

38. Canepari, P.; Boaretti, M.; Lleo, M.M.; Satta, G. Lipoteichoic acid as a new target for activity of antibiotics: Mode of action of daptomycin (LY146032). Antimicrob. Agents Chemother. 1990, 34, 1220-1226.

39. Wang, M. Surface modification of biomaterials and tissue engineering scaffolds for enhanced osteoconductivity. In Proceedings of the 3rd Kuala Lumpur International Conference on Biomedical Engineering, Kuala Lumpur, Malaysia, 11-14 December 2006; pp. 22-27.

40. Menzies, K.L.; Jones, L. The impact of contact angle on the biocompatibility of biomaterials. Optom. Vis. Sci. 2010, 87, 387-399.

41. Tegoulia, V.A.; Cooper, S.L. Staphylococcus aureus adhesion to self-assembled monolayers: Effect of surface chemistry and fibrinogen presence. Colloid. Surf. B 2002, 24, 217-228.

42. Mitik-Dineva, N.; Wang, J.; Truong, V.; Stoddart, P.; Malherbe, F.; Crawford, R.; Ivanova, E. Escherichia coli, Pseudomonas aeruginosa, and Staphylococcus aureus attachment patterns on glass surfaces with nanoscale roughness. Curr. Microbiol. 2009, 58, 268-273.

43. Katsikogianni, M.G.; Missirlis, Y.F. Interactions of bacteria with specific biomaterial surface chemistries under flow conditions. Acta Biomater. 2010, 6, 1107-1118.

44. Balazs, D.J.; Triandafillu, K.; Chevolot, Y.; Aronsson, B.O.; Harms, H.; Descouts, P.; Mathieu, H.J. Surface modification of PVC endotracheal tubes by oxygen glow discharge to reduce bacterial adhesion. Surf. Interface Anal. 2003, 35, 301-309. 
45. James, N.R.; Jayakrishnan, A. Surface thiocyanation of plasticized poly(vinyl chloride) and its effect on bacterial adhesion. Biomaterials 2003, 24, 2205-2212.

46. Riedewald, F. Bacterial adhesion to surfaces: The influence of surface roughness. PDA J. Pharm. Sci. Technol. 2006, 60, 164-171.

47. Howell, D.; Behrends, B. A review of surface roughness in antifouling coatings illustrating the importance of cutoff length. Biofouling J. Bioadhesion Biofilm Res. 2006, 22, 401-410.

48. Ivanova, E.P.; Truong, V.K.; Wang, J.Y.; Berndt, C.C.; Jones, R.T.; Yusuf, I.I.; Peake, I.; Schmidt, H.W.; Fluke, C.; Barnes, D.; Crawford, R.J. Impact of nanoscale roughness of titanium thin film surfaces on bacterial retention. Langmuir 2010, 26, 1973-1982.

49. Bazaka, K.; Jacob, M.V.; Ivanova, E.P. James Cook University, Townsville, Australia. Unpublished work, 25 January 2011.

50. Belsito, D.; Bickers, D.; Bruze, M.; Calow, P.; Greim, H.; Hanifin, J.M.; Rogers, A.E.; Saurat, J.H.; Sipes, I.G.; Tagami, H. A toxicologic and dermatologic assessment of cyclic and non-cyclic terpene alcohols when used as fragrance ingredients. Food Chem. Toxicol. 2008, 46, S1-S71.

51. Van Oss, C.J.; Good, R.J.; Chaudhury, M.K. Role Of van der waals forces and hydrogen bonds in 'hydrophobic interactions' between biopolymers and low energy surfaces. J. Colloid Interface Sci. 1985, 111, 378-390.

52. Van Oss, C.J.; Good, R.J.; Chaudhury, M.K. Additive and nonadditive surface tension components and the interpretation of contact angles. Langmuir 1988, 4, 884-891.

53. Öner, D.; McCarthy, T.J. Ultrahydrophobic surfaces. Effects of topography length scales on wettability. Langmuir 2000, 16, 7777-7782.

54. Guy, D.W.; Crawford, R.J.; Mainwaring, D.E. The wetting behaviour of several organic liquids in water on coal surfaces. Fuel 1996, 75, 238-242.

(C) 2011 by the authors; licensee MDPI, Basel, Switzerland. This article is an open access article distributed under the terms and conditions of the Creative Commons Attribution license (http://creativecommons.org/licenses/by/3.0/). 